\title{
Optimization of Packaging Process Parameters using Combined Taguchi Method-Present Worth Method/ Inflationary Factor Validated
}

\author{
S.A. Oke* and I.O. Fagbolagun
}

\begin{abstract}
In a previous article, the packaging optimization literature illustrated how to optimize the packaging parameters using the classical Taguchi approach. Notwithstanding, it is compelling to bridge the gap created in the article for further advancement. Thus, this paper contributes to expanding scholarship regarding the area. The paper targets the Taguchi methodical optimization literature in which several scores of research across engineering disciplines and beyond have been undertaken. At present, evaluation using the Taguchi method often stops at the determination of the optimal settings from the response table through a chain of steps from factor-level selection, orthogonal array choice, signalto-noise determination, and response table evaluation to emerge the optimal parameters. There is no information on the economic aspects of the parameters, yet processes are expected to be sustainable while economic factors play a central role. A novel idea of the present work is introduced where the interest rate and inflationary factor with levels are used to determine the economic strength of each parameter through ranking. Data was collected from a brewery process, and literature data concerning cold arc welding parametric evaluation was used. The outcome demonstrates the workability of the method in the packaging plant and cold arc welding process. The work is useful for packaging managers and welding engineers for planning purposes.
\end{abstract}

Keywords: Taguchi method, signal to noise ratio, interest rate, inflation rate, optimization.

Article Info: Received October 31, 2020; Revised April 14, 2021; Accepted July 1, 2021.

\section{INTRODUCTION}

In some bottling process plants, the packaging unit is a complete production process whereby all production activities from raw material receipts to their transformation and then enclosing the finished products into defined packs are accounted for (Aerts and Smits, 2017; Karabegović and Đuzelić, 2019; Abafi and Oke, 2020). In a previous article, Fagbolagun and Oke (2020) optimized the process parameters of a packaging system using the classical Taguchi framework. However, the working system of the brewery is complicated and should be modeled such that the impacts of the employees are aligned with the target of the plant. This may lead to the packaging process multi-disciplinary modeling in the context of the inter-relationship of the workforce with the sister companies. It is also linked to the financial houses giving out loans to the organization, which ascertain the ability of the organization to pay back. To clarify, the packaging engineer leads his/her team in a complicated brewery operation. The brewery makes products for satisfying the national and exports markets. It connects with associated plants within the nation to ascertain that products are delivered to both customers and other plants that make up their product shortages with the company's products at optimized cost. This paper reexamines the circumstances guiding the development of the optimal parametric setting in the previous paper. The present worth factor is amalgamated with the signal-to-noise ratio to give a

\footnotetext{
S.A. Oke* is with the Department of Mechanical Engineering, University of Lagos, Nigeria (email: sa_oke@yahoo.com).

* Corresponding author
} 
financial perspective of the performance of the packaging team.

The optimization has been considered in the packaging system as an essential task for the bottling process plant (Fagbolagun and Oke, 2020). In optimizing the system, the Taguchi scheme has been declared as a necessity: Üstüntağ et al. (2020), Sousa et al. (2020), Almetwally (2020); Al-Refaie (2015), AlRefaie et al. (2014), Anthony (2001), Athreya and Vankatesh (2012), Blackhall et al. (2006), Candan and Yazgan (2015), Chomsamutz and Jongprasithporn (2012), Chandrasekar et al. (2015), Chen et al. (2009), Chen and Huang (2006), Dwiwedi and Kumar (2015), Ganesan and Kaliyamoorthy (2020), Ishrat et al. (2019) and Jon et al. (2014). In these articles, to give a clearer idea of what has been done and the gap filled by the current work, concise mentioning of the factors under study, the response variables, and the important results are given. In Al-Refaie (2014), two groups of factors were studied in two separate illustrations. The first illustration concerns the sputtering process, which was optimized. The factors are the sputtering pressure, postannealing temperature, RF power, substrate temperature, and deposition time, while the response variables analyzed are the deposition rate and optical transmittance, and electrical resistivity. For the second illustration, the wire electrical discharge machining process, the process factors are the wire feed speed, pulse in time, and delay time. At the same time, the response variables examined are the surface roughness and material removal rate. The important results are that the proposed approach tackled the inbuilt variability and variability observed in several responses through preference analysis. While this work is relevant in that it promotes ideas on the Taguchi scheme, what is yet to be covered is some analysis based on the economic/financial aspect to include the present worth, interest rate, and inflation rate.

Furthermore, Al-Refaie (2015) offered an interesting discussion on a weight additive model aimed at optimizing responses in a Taguchi approach. A wide range of four illustrations was made. In the first illustration, the welding process called the submerged arc was analyzed for factors (welding speed, pre-heat temperature, arc voltage, electrode protrusion, and arc current) and responses (dilution and deposition rate). For the second illustration, an electric discharge machining process with the Inconel 718 input was considered. Here, the ignition current, pulse on time, wire feed speed, and delay time were taken as factors, while the response variables are the surface roughness and material removal rate. For the third illustration, the wire electric discharge machining was considered with the particle-fortified 6061 alloys. In this case, the factors are off time of discharging, wire feed, the radius of the work material, arc on time of discharge, on-time of discharging, arc off time of discharging, water flow, and servo voltage. However, the response variables are the surface removal rate and the surface roughness. For the fourth illustration, the plastic pipe extrusion process was used. The identified factors are motor speed, temperature, and vacuum, while the response variables are thickness and diameter. For the article, the important result is that the proposed method competently optimized the responses. Although the work adds to knowledge in theory and practice on Taguchi methods, it is not useful to establish the particular factors relevant to a brewery process. Besides, there is no hint on how the economic/financial aspects of the production process, vis-à-vis, and the present worth method, interest, and inflation could be incorporated into the solution as a concurrent optimization and economic analysis brewery process.

Nevertheless, in another contribution, Candan and Yazgan (2014) mentioned the factors to represent a flexible scheduling problem in manufacturing as the crossover approach, derivation approach, crossover rate, population size, and mutation rate while the perceived response is the $C_{\max }$. The principal result of the study is the fewer iterations of 3780 that the method proposed by the author yielded (the genetic algorithm parametric optimization by deploying the Taguchi scheme). This exceeds the output of full factorial experimentation of 34,020 iterations. Though the application domain is similar to the current study, the parameters established to represent the brewery operation's case are different. Besides, no economic/financial issues were considered in work.

To further reveal what has been done, the contribution of Dwiwedi and Kumar (2015) is important. The selected factors to represent the injection molding process studied are the injection speed, cooling time, injection pressure, and processing temperature. However, the tensile strength was considered as the representative response and adopted for the signal-tonoise analysis. The main result is that the processing temperature was the first choice among the parameters because it is the most effective. However, the injection speed ranked next, followed by the injection pressure and, lastly, the cooling time. Although important results were obtained from work, there is still the gap of economic and financial factors not tackled by the work. Furthermore, how to pick the correct process parameters for a brewery process is not clear.

Furthermore, the work of Chandraskar et al. (2015) was found relevant to the present work. The authors worked on the ready-to-eat peanut chutney to establish the storage temperature, vinegar, and packaging material as process materials. At the same time, the responses were taken as the free fatty acid composition, the value of peroxide from the sample, the phenolic content, and the overall acceptability of the developed food product. The study's key result is that all the studied factors were observed to appropriately affect the quality attribute after the $40^{\text {th }}$ day. Nonetheless, despite this contribution, a direct lead on determining the factors for a brewery process was not given. Furthermore, the issue of economic/financial factors and their influence on the brewery process was downplayed.

In Almetwally (2020), the mentioned factors are the twist multiplier, fabric weave structure, and weft yarn count and weft density. However, the established 
responses are the breaking elongation, air permeability, and tensile strength. With the use of the combined Taguchi method and grey relational analysis, the main results are that the most effective factors to enhance the fabric performance are the weft yarn linear density, and the fabric weaves structure. However, the twist factor and weft density had low contributions. Weighted against the present work, there is no clear way of evaluating the present work using economic/financial issues, but it remains a gap.

Besides, while operating the packaging unit, funds are sourced from financial outlets, but the ability to repay debt is critical to the bottling plant's survival. However, at present, most literature, for instance, those listed above to justify Taguchi methods applications, extensively draw from the technical activities of the systems that they model. Additionally, evidence abounds also in the following papers that the literature is completely one-sided, focusing on the technical activities of production but are run independently of economic activities: Grobbel et al. (2008), Zagloel and Al-Aina (2009), Karimi et al. (2013), Fang et al. (2017), Heide and Olsen (2017), McMillin (2017) and Steenis et al. (2017).

Although optimization of the packaging process is compelling, an excellent technical team with optimized performance according to the technical details alone may not be working for a company that shows signs of economic instability and collapse potential. This is the shortcoming of the classical Taguchi method; it lacks comprehension and the ability to detect the financial status and performance of the packaging team while working at optimal performance. Based on this gap, an excellent technical team may suffer setbacks if the company's financial position is poor and the management is unable to pay its debt. However, if linked to the economic aspects, the activities of the technical crew may be better controlled.

To date, there is an absence of a mechanism to couple the optimization activities in the packaging unit with the economics of the plant (Hamdar et al., 2018). This poses a continuous risk to the plant's survival as the technical crew is unable to determine when the economic health status of the packaging plant is satisfactory or not. To bridge this gap, the paper addresses how to integrate the Taguchi technique with the present worth method and the inflationary factor for concurrent optimization and economic evaluation of the packaging plant. Taguchi method is innovative, requiring less computational time, cost, and is easy to use. It permits the opportunity to determine the significant factors influencing quality characteristics. The present worth method uses the interest rate as an economic indicator for the healthy state of the plant while inflation reacts to the forces of demand and supply in an economy.

To place this article in the context of the packaging literature, a brief mention of some packaging papers is made. Fang et al. (2017) revised the concept of intelligence in packaging as applied to the meat industry. The following authors examined packaging attributes: Silayoi and Speece (2007), Grobbel et al. (2008),
Zagloel and Al-Aina (2009), Karimi et al. (2013), Steenis et al. (2017), Heide and Olsen (2017), and Karabegović and Đuzelić (2019). In Heide and Olsen (2017), the mentioned factors were distinguished into two: visual and informational factors. For visual factors, the color of the packaging and shape were captured. However, taste information, shelf life, freshness statement, freshness indicator, and convenience were captured under the informational factors. The study's main finding was that consumers preferred the visual factors of color and shape. While these factors are important in packaging, the study has not provided a clear insight into how the packaging system's economic/financial factors could be incorporated into the optimization process.

Furthermore, Karabegović and Đuzelić (2019) mentioned the thermoforming process parameters within the packaging system to comprise two groups: when foil heating is the response, the factors captured are the heating time, and the heating temperature. However, when the foil forming is the response, the forming pressure, forming temperature, and the forming time are the factors. The study's key findings are mainly regarding the foil heating at the optimum temperature, which was attained at $87^{\circ} \mathrm{C}$. However, the normal foil heating temperature was between $80^{\circ} \mathrm{C}$ and $120^{\circ} \mathrm{C}$. Furthermore, the optimum time for heating was obtained as 2 seconds. While it is agreed that the study is within the packaging domain and of similar characteristics to the present study, the perspective of analyzing the problem is different from the present study. Furthermore, there is no incorporation of economic/financial factors into the modeling of the optimization process. A research gap addressed by the present work concerns the economic aspect of packaging.

Nevertheless, Hamdar et al. (2018) analyzed the economic aspect of the packaging and could be judged to be in the same domain as the present study. The principal factors considered in work include packaging color, label, packaging quality, packaging design, printed information, communication, and innovation. While the study contributes to knowledge, it is doubtful if it offers a direct lead to the optimization of packaging parameters in concurrence with the economic/financial factors. Nevertheless, in all these studies, only the study by Hamdar et al. (2018) has elaborated on packaging economics.

Lastly, a review of literature is pursued about studies applying the present worth method. The present worth method has an important role in serving as an efficient analysis approach to establishing the performance acceptability of a brewery process from an economic standpoint. However, it is unclear how the method could be applied to the packaging process plant from previous studies. In this review, two aspects are considered. The first concerns studies that deal with crisp numeric values in evaluating the present worth of a project, while the second considers uncertainty and hence applied fuzzy concepts to propose new methods.

First, the method of crisp numeric values is 
considered. Here, Zizlavsky (2014) applied that net present value method to evaluate the aspect of innovative performance evaluation. The author discussed the potential of the method to analyze the probable financial value of the system being analyzed. Besides, Doss et al. (2014) analyzed the condition of an academic institution using the net present worth to establish the total degree program in the institution.

The second set of papers with uncertainty attributes in their analysis follows. As early as more than 25 years ago, the importance of the present worth analysis was demonstrated by Chiu and Park (1994) in a cash flow study. It was appreciated that uncertainty occurs in engineering economic analysis, and a fuzzy cash flow idea using the criterion of present worth was essential in theory and practice. The outcome of the present worth was a fuzzy number having a membership function of the non-linear type but estimated using the triangular fuzzy number. The numerical application of the work showed the effectiveness of the proposed method.

Along with the domain of uncertainty analysis, Kahraman (2001) applied uncertainty principles to discounted cash flow with emphasis on fuzzy present value, fuzzy payback period, fuzzy equivalent uniform annual value, fuzzy benefit-cost ratio, and fuzzy future value. Within the context of uncertainty analysis, Kuchta (2008) proposed the fuzzy net present value analysis. The proposed work also treated the fuzzy and probabilistic method to analyze the present value and maximize the fuzzy net present value. Ulukan and Ucuncuoghi (2010) appraised the economic aspect of an information system project by deploying the fuzzy present value concept together with the fuzzy $B / C$ quotient and established the workability of the approach using numerical examples. Furthermore, Appadoo (2014) analyzed the present value method by using the fuzzy concept. The author elaborated on the probabilistic theory and obtained closed-form computations regarding the fuzzy probabilistic net present value. Maravas and Pantouvakis (2018) established the principal indicators of cost-benefit analysis using the fuzzy internal rate of return and demonstrated its feasibility in a motorway project.

\section{RESEARCH METHODOLOGY}

In this study, the interest rate and inflation factor are applied individually and jointly to influence the traditional Taguchi methodical optimization for packaging process parameters. The argument is that the packaging process may only be sustained if the performance analysis of the system is tied to economic parameters of interest rate and inflation factor. At every financial year, money is borrowed to run the packaging operations from financial institutions, and the capability to repay the interest and capital has been independently treated in the literature. Unfortunately, there is no linkage with the workers' performance being driven by economic factors. So the interest rate is considered a driver to link the workers' activities and outcomes (value-adding activities) to the ability of the packaging plant to repay the debt borrowed from financial houses. This is the first aspect of the work. Furthermore, the packaging plant works in an environment subjected to the market forces of demand and supply. Changes occur in the prices of the raw materials, salary adjustments, and other financial obligations of the packaging plant. To date, no association is made concerning the optimization of the parameters controlling the process and the inflationary factor. It is thought that bringing this idea of inflationary factor into the analysis of packaging parameters in optimization will contribute to scientific progress in the area.

The first phase of the research involves the establishment of an optimal parametric setting based on the traditional Taguchi scheme. An extension is to introduce the present worth concept based on the interest rate to evolve ranks with which each parameter may be compared. Two outcomes emerged from here: optimal parameters in the traditional form and newly determined present worth values regarding the interest rate with ranks as outputs. The second phase of the research regards the establishment of optimal parametric settings where the signal-to-noise ratio has been modified to include interest rate in a new name called interest ratebased signal-to-noise ratio. The outcome of the phase is the optimal parametric value determination in a new context of an infused interest rate form.

The third phase of the research concerns the determination of the optimal parametric setting using the traditional approach and the introduction of a new concept of present worth approach that incorporates both the interest rate and inflationary factor in a multiplicative manner. The outcome of this phase is to create optimal parametric values and newly developed present worth values for each parameter with ranks. The fourth phase of the study concerns the determination of the optimal parametric setting with an amended signalto-noise ratio incorporating the inflationary factor. The present worth is then established based on interest rate alone to yield ranks. The fifth phase of the study regards the establishment of the optimal parametric setting based on a new signal-to-noise ratio computation that accounts for the multiplicative action of the interest rate and inflation factor. The optimal parametric setting is then established.

In this section, the reasons for the order in which the research was used (from the first to the fifth stage) are given. The present worth represents the amount of cash available today, which corresponds to a value in payment for the future. Nevertheless, the present value uses an interest rate that may be earned if invested. Thus, Case 1 that deals with the optimal parametric setting and present worth, and (Case 2, which uses the interest rate and the optimal parametric setting are pursuing the same objective of monitoring the rate of interest in the packaging plant and takes the first order in the analysis of cases. However, while planning for the strategies and operational activities in a packaging plant, establishing both the interest rate and the present worth factor is important. Consequently, using these ideas to ascertain the status and trend of performance within the packaging 
plant is of substantial importance. The interest rate is important because it is part of the company's economic system that reveals the possible economic and financial tasks that the organization can engage in.

The next in the order of research for the presented cases relates to the incorporation of the inflation factor in the computation. This is contained in the rest of the cases, such as Case 3, Case 4, and Case 5. In these cases, the inflation factor is introduced. This describes the increase in prices of the goods and services offered by the packaging plant without a corresponding increase in the quality of the products or services. Inflation in the economic status of the company and government strives to keep inflation under control. The inflation rate is a crucial factor as the manager of the packaging plant decides on the economic progress of the packaging plant. The reason attributable to close monitoring of inflation is that it grows the burden of debt since inflation offsets the interest rate.

\subsection{The selected factors}

The factors investigated in the paper are four, namely, beer-filled into the filler (HL), total time available (hrs), hectolitres into FBS, and crates into FBS and are represented as codes $B, H, C, T$, respectively. These were considered as a substantial influence on beer waste. A common technology in the brewery system is to operate the beer dispenser to fill the beer from the bottom; a technology called bottom-up. To illustrate the working of this technology, imagine cups being placed on top of the dispenser. The bottom-up know-how allows the complete pouring of the beer from the bottom of the glass. With holes at the bottom of the cups, the technology of the holes is encompassed by a functioning metal ring that allows the sealing of the bear through the action of a magnet. As the cup is positioned on the dispenser, the technology permits the magnet to lift, and the beer flows in. Since the objective of the article is to eliminate waste, the know-how is developed to precisely deal with these wastes as the dispenser pours the right amount of beer foam into the cup each time it is operated.

\subsection{The reasons for selecting factors}

In the packaging system of the beer production system, there are many types of equipment and/or process experimental variables that dictate the competence of the system to achieve the intended goal. These are PET/glass/beer can filler, cappers, washers, caps, racks, labels, and corkers. A challenge is to choose the key factors (parameters) that are bottlenecks, and providing a solution to this bottleneck will enhance the system performance in output generation. While installing optimization techniques for the beer production process, establishing the amount of beer issued into filler is a necessary endeavor. In this regard, analyzing the performance of the filling valves from the beer filler in the brewery is of substantial value. The performance of the filler is important because it works on a counter pressure to open and allow the flow of beer to the bottle. To achieve this, a slow release of pressure through the vent is experienced such that $\mathrm{CO}_{2}$ is permitted to escape, paving the way for beer to flow. Thus, any technical error or miscalculation of the operator may substantially be responsible for complete failure and wastage of the beer in the process.

Furthermore, industrially brewed beer, of measured quantity in hectolitre, which is a key unit of volume used globally in the brewery industry, is a significant factor to incorporate in a study to choose the prominent packaging system parameters in beer packaging. The reason is that leakages may threaten the beer production in the industry in the system, and the amount in hectolitres delivered into the next stage after filling for further processing is an important concern in the packaging system optimization process. Besides, in the selection process of packaging parameters for beer production, there is scope to include the number of creates produced. An opportunity to enhance production is the installation of quality checks at the crate packaging unit, where they are batched in units to containers (packaged). The total time available for services is an essential parameter to consider as the packaging manager decides on the selection of important parameters in the system. The justification for this is that during the brewing process, beers are conditioned such that the principal elements, including sugar, time, yeast, and temperature, dictate the condition of the beer. For a prolonged time, other elements are affected, and the preservation of the beer produced may not be guaranteed.

\subsection{Procedure to implement Taguchi method- present worth method}

In this method, the Taguchi method and the present worth method are amalgamated. By merging these methods, a decision model is created which incorporates the time value of money that will assist the management of the packaging industry in making enhanced and informed decisions. However, at the same time, the manager stands the risk of making sub-optimal decisions and thereby making wrong decisions for the packaging business. Fortunately, bringing in the Taguchi method solves this problem of sub-optimality. So, the model

Table 1. Factors and levels (Fagbolagun and Oke, 2020)

\begin{tabular}{|c|l|c|c|l|}
\hline \multirow{2}{*}{ Code } & \multirow{2}{*}{ Factors } & \multicolumn{3}{|c|}{ Levels in coded form } \\
\cline { 3 - 5 } & & 1 & 2 & Units \\
\hline B & Beer issued into filler & 5,697 & 25,693 & HL \\
\hline H & Hectolitres into FBS & 5,020 & 23,605 & HL \\
\hline C & Crates into FBS & 69,728 & 298,031 & Units \\
\hline T & Total time available & 84 & 300 & Hrs \\
\hline
\end{tabular}


concurrently optimizes parameters while accounting for the time value of money, which creates the consciousness in the workers that every minute spent in the company is important. The point of amalgamation is after the optimal setting has been defined. The following steps are applicable to achieve the method.

Step 1: Obtain factors and levels from the process.

Step 2: Obtain the relevant orthogonal matrix for the problem.

Step 3: Set up the factor table such that the elements of the orthogonal arrays are mapped to the values of each factor with level to provide a platform to migrate to the signal to noise ratio computation.

Step 4: Draw out the signal to noise aspect of computation by considering the goal of the experiment along with three criteria of lower the better, nominal the best, and the higher, the better.

Step 5: Obtain the response table by working with the signal to noises ratios and the pattern generated by the orthogonal array for the levels. The values of the signal-to-noise ratio for all entries at a level are averaged.

Step 6: Obtained the optimal parametric values by choosing the maximum signal-to-noise ratio under each level.

Step 7: $\quad$ Fix as the level for each parameter and I as the interest rate to comprise the present worth for each parameter. Considered the beneficial and non-beneficial factors in the analysis as they occupy the different sides of the performance diagram. The beneficial side is the upper side, and the nonbeneficial on is the lower side.

Step 8: Determine the present worth of each parameter.

Step 9: Rank the parameters according to the highest to the lowest values.

The criteria for computing the signal-to-noise ratios are as follows:

Larger is better: $S / N=-10 \log \frac{1}{n} \sum \frac{1}{y^{2}}$

Nominal is best: $S / N=-10 \log \left(\sigma^{2}\right)$

Smaller is better: $S / N=-10 \log \frac{1}{n} \sum y^{2}$

where, $n=$ sample size, and $y=$ beer waste (HL) in that run.

The following cases are considered:

Case 1 - Determine $S / N$ ratios, optimal parametric settings, and present worth values. For Case 1, Equation (3) is the $S / N$ ratios generating criterion considered. Equation (4) is also used.

$P W_{B / H / C / T}=L(1+i)^{-n}$

where $P W_{B / H / C / T}$ is the present worth, and $L$ represents the value of the parameter at particular levels.
Case 2 - Determine $S / N$ ratios (with interest rate), optimal parametric settings. For Case 2, Equation (4) is the $S / N$ ratios generating criterion considered.

Smaller is better: $S / N=i\left(-10 \log \frac{1}{n} \sum y^{2}\right)$

where $n$ is the sample size, and $i$ represents the interest rate.

Case 3 - Determine $S / N$ ratios, optimal parametric settings and present worth with inflation factor. For Case 3, Equation (3) is the $S / N$ ratios generating criterion considered. Equation (6) is also used.

$$
P W_{B / H / C / T}=\left[L(1+i)^{-n}\left[(1+\beta)^{n}\right]\right.
$$

where $P W_{B / H / C / T}$ is the present worth, and $L$ represents the value of the parameter at particular levels, $n$ is the position at which the parameter is and $\beta$ is the inflationary factor.

Case 4 - Determine $S / N$ ratios (with inflation factor), optimal parametric setting, and present worth values.

Smaller is better: $S / N=\beta\left(-10 \log \frac{1}{n} \sum y^{2}\right)$

where $n$ is the sample size and $\beta$ is the inflationary rate.

Case 5 - Determine $S / N$ ratios (with interest rate and inflation factor), optimal parametric setting.

Smaller is better: $S / N=\beta_{i}\left(-10 \log \frac{1}{n} \sum y^{2}\right)$

where $n$ is the sample size, and $i$ represents the interest rate and $\beta$ is the inflationary rate.

\section{RESULTS AND DISCUSSIONS}

This section collates all the results obtained from the analysis of the data collected using the Taguchi method. Typical data from a bottling industry's packaging lines were collected and analyzed to determine the factor settings to yield the least hectolitres of beer waste. Hence, four factors, namely, beer-filled into the filler (HL), total time available (hrs.), hectolitres into FBS, and crates into FBS, were considered to measure their influence on beer waste. Taguchi's smaller-the-better signal-to-noise ratio and ANOVA were used to screen the key factors which minimized the beer waste of the industry.

In this paper, five cases are defined, Cases 1 to 5 , with the distinguishing feature being whether or not an inflationary factor and/or interest rate is incorporated in the optimal parametric determination and the eventual final value of the method. In Case 1 , the $\mathrm{S} / \mathrm{N}$ ratios are determined, and optimal parametric settings are established at the first phase, while the second phase entails the computation of the present worth. For Case 2 , at the determination of the $\mathrm{S} / \mathrm{N}$ ratios, a separate column is created for the interest rate and then multiplied by the $\mathrm{S} / \mathrm{N}$ ratios to obtain interest rateenhanced $\mathrm{S} / \mathrm{N}$ ratios. The optimal parametric settings are then established. Case 3 is a two-phase system where the $\mathrm{S} / \mathrm{N}$ ratios are first determined, and the optimal parametric setting is then decided. The second phase is 
the deployment of a method that incorporates both the present worth and inflationary factor. Case 4 is also of two phases, notably the determination of $\mathrm{S} / \mathrm{N}$ ratios where a column is created for inflationary factor to obtain an inflation-based $\mathrm{S} / \mathrm{N}$ ratio. The second stage is the computation of the present worth values. Case 5 involves determining the $\mathrm{S} / \mathrm{N}$ ratios where two extra columns are created. These extra columns are for the interest rate and inflation factor. A final interest rateinflation factor-based $\mathrm{S} / \mathrm{N}$ ratio is then computed.

\subsection{The analysis of experimental results of the Taguchi methodology}

In this paper, four factors and two levels are used to represent the packaging system. The four factors are determined after a thorough analysis of the key factors of the system, and the levels are the outcomes of the reallife instance. To determine the levels, each factor was considered over a range of production data while the minimum and maximum values were chosen in the array of production figures. Consequently, the $L_{16}$ orthogonal array was selected. This permitted a repetition of the experiments sixteen times to confirm results and afford the researchers the opportunity to learn more about the packaging process being studied.

In applying the design of experiment principles, the parameters are identified as the beer in the filler, crates in FBS, hectolitres in FBS, and total time available. At the same time, the response was defined as beer waste. In the brewing process, three principal wastes, notably the spent grains obtainable from brewing, residual yeast obtainable from the bottom of the tank, and the sludge, are generated. Although these wastes may be used for incineration, composting, dumping, and recycling, they erode the company's profit and should be monitored, controlled, and minimized. This gives room to the lean program currently implemented in the brewing industry globally. The experimental design incorporates the use of an orthogonal array, factors and levels, determination of the original-to-noise ratio, response table development, and the identification of the optimal parametric setting. The signal-to-noise ratio is regarded as the objective function, which is related to the minimization of beer waste produced from the packaging system.

\subsection{Case 1 - Determine $\mathrm{S} / \mathrm{N}$ ratios, optimal parametric settings, and present worth values}

From Table 2, it is desired to create a response table, which is the averages regarding the orthogonal array entries of Table 2 to be created while also considering Table 3. Consider the matrix in Table 3. Each cell is an intersection of a column and a row. An instance is $B_{1}$, which is the intersection between column $B$ and row 1 . To obtain the value here, Table 2 is referred to and all the values under the orthogonal array, within column $B$, for experimental numbers 1 to 8 , which have the level of 1 , corresponding to row 1 the level of 1 of Table 3 is used.

To sum up, consider each of the corresponding values in the column for $\mathrm{S} / \mathrm{N}$ ratios. For experimental numbers 1 to 8 , which begin from -90.90 (Experiment 1) to 103.49 (Experimental 8), the mean of the values is 97.30. To obtain the average value for cell $B_{2}$, the corresponding values mapped to experiments 9 to 16 under $\mathrm{S} / \mathrm{N}$ ratios but referring to column $B$ are used. Similarly, an average of -86.14 is obtained. By following the same procedure, the values in the cells $H_{1}$, $H_{2}, C_{1}, C_{2}, T_{1}$, and $T_{2}$ could be obtained respectively as $97.32,-97.54,-91.37,-103.50,-97.43$, and 97.43 .

In this work, the signal-to-noise ratios for each mapping factor to level in the Taguchi design are computed. The goal of this experiment is to reduce the beer waste, and the signal-to-noise ratio having the

Table 2. $\mathrm{L}_{16}$ orthogonal array, four factors, and $\mathrm{S} / \mathrm{N}$ ratio values using Taguchi method

\begin{tabular}{|c|c|c|c|c|c|c|c|c|c|}
\cline { 2 - 11 } & \multicolumn{3}{c|}{ Orthogonal array } & \multicolumn{6}{c|}{ Factors } \\
\hline $\begin{array}{c}\text { Expt. } \\
\text { No. }\end{array}$ & B & H & C & T & B & H & C & T & S/N ratio \\
\hline 1 & 1 & 1 & 1 & 1 & 5697 & 5020 & 69728 & 84 & -90.90 \\
\hline 2 & 1 & 1 & 1 & 2 & 5697 & 5020 & 69728 & 300 & -90.90 \\
\hline 3 & 1 & 1 & 2 & 1 & 5697 & 5020 & 298031 & 84 & -103.47 \\
\hline 4 & 1 & 1 & 2 & 2 & 5697 & 5020 & 298031 & 300 & -103.47 \\
\hline 5 & 1 & 2 & 1 & 1 & 5697 & 23605 & 69728 & 84 & -91.34 \\
\hline 6 & 1 & 2 & 1 & 2 & 5697 & 23605 & 69728 & 300 & -91.34 \\
\hline 7 & 1 & 2 & 2 & 1 & 5697 & 23605 & 298031 & 84 & -103.49 \\
\hline 8 & 1 & 2 & 2 & 2 & 5697 & 23605 & 298031 & 300 & -103.49 \\
\hline 9 & 2 & 1 & 1 & 1 & 25693 & 5020 & 69728 & 84 & -91.42 \\
\hline 10 & 2 & 1 & 1 & 2 & 25693 & 5020 & 69728 & 300 & -91.42 \\
\hline 11 & 2 & 1 & 2 & 1 & 25693 & 5020 & 298031 & 84 & -103.50 \\
\hline 12 & 2 & 1 & 2 & 2 & 25693 & 5020 & 298031 & 300 & -103.50 \\
\hline 13 & 2 & 2 & 1 & 1 & 25693 & 23605 & 69728 & 84 & -91.82 \\
\hline 14 & 2 & 2 & 1 & 2 & 25693 & 23605 & 69728 & 300 & -91.82 \\
\hline 15 & 2 & 2 & 2 & 1 & 25693 & 23605 & 298031 & 84 & -103.52 \\
\hline 16 & 2 & 2 & 2 & 2 & 25693 & 23605 & 298031 & 300 & -103.52 \\
\hline
\end{tabular}

B - Beer issued into filler (HL); H - Hectolitres into FBS (HL); C - Crates into FBS (Units); T - Total time available (hours); $\mathrm{S} / \mathrm{N}$ ratio - Signal-to-noise ratio 
Table 3. Taguchi average SN ratio response table

\begin{tabular}{|c|c|c|c|c|}
\hline Level & B & H & C & T \\
\hline 1 & -97.30 & $-97.32^{*}$ & $-91.37^{*}$ & $-97.43^{*}$ \\
\hline 2 & $-86.14^{*}$ & -97.54 & -103.50 & $-97.43^{*}$ \\
\hline Delta & 11.16 & 0.22 & 12.13 & 0 \\
\hline Rank & 1 & 3 & 2 & 4 \\
\hline
\end{tabular}

*optimum values

Beneficial side

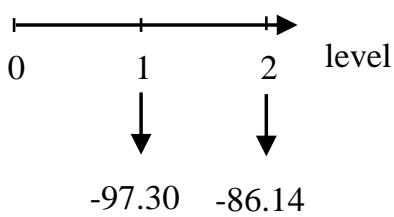

Non-beneficial side

Figure 1a. Present worth for parameter B

Beneficial side

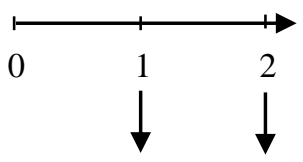

$-91.37-103.50$

Non-beneficial side

Figure 1c. Present worth for parameter C
Beneficial side

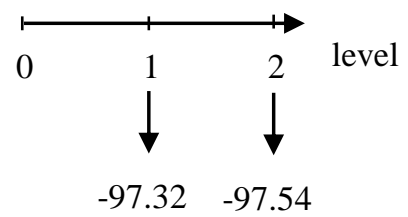

Non-beneficial side

Figure 1b. Present worth for parameter $\mathrm{H}$

Beneficial side

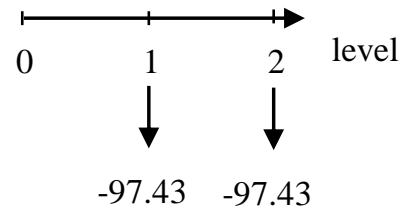

Non-beneficial side

Figure 1d. Present worth for parameter T

Table 4. Present worth at optimal values of Taguchi method

\begin{tabular}{|l|c|c|c|c|}
\hline & $\mathrm{PW}_{\mathrm{B}}$ & $\mathrm{PW}_{\mathrm{H}}$ & $\mathrm{PW}_{\mathrm{C}}$ & $\mathrm{PW}_{\mathrm{T}}$ \\
\hline Value & -155.55 & -164.65 & -164.90 & -164.66 \\
\hline Rank & 1 & 2 & 4 & 3 \\
\hline
\end{tabular}

minimum value is chosen. The parametric values are the optimal $\mathrm{S} / \mathrm{N}$ values whose corresponding values may be read from Table 3 . The optimal $\mathrm{S} / \mathrm{N}$ ratios are $B_{2} H_{1} C_{1} T_{1}$ or $B_{2} H_{1} C_{1} T_{2}$. This means $25,693 \mathrm{HL}$ of beer issued into filler with 5,020 HL of hectolitres into FBS and 69,728 units of crates into FBS, and 84 hours of the total time available. The alternative solution is $25,693 \mathrm{HL}$ of beer issued into filler together with 5,020 HL of hector liters into FBS as well as 69,728 units of the crate into FBS and finally 300 hours of the total time available. The reason for having two solutions is that the delta values produced zero for the time, $T$ factor. It means that either of the values of $T$ in levels 1 and 2 could be used, and there will not be a difference in results.

Finally, the ranking of the parameters is that $B$ is ranked $1^{\text {st }}$ followed by $C, H$, and $T$ as $2^{\text {nd }}, 3^{\text {rd, }}$ and $4^{\text {th }}$, respectively. This is a reflection of how sensitive these parameters are in the system. It informs the packaging manager of the brewery that the most outstanding effort to improve the performance of the packaging system should concentrate on the filling unit, while changes in the time allocated to production should be the least to change.
In the classical application of the Taguchi method to process optimization problems, the outcome has always been the establishment of the optimal parametric setting, which had been declared in the previous paragraph. However, there is a necessity to innovate the process of optimizing these variables by introducing the engineering economics principle such that the alternative parameters could be further evaluated to differentiate them from one another regarding their economic strength. This becomes a method of concurrent optimization and economic analysis using the combined Taguchi method and the present worth analysis method. To analyze using the present worth method, Equation (2) is introduced. This starts with the computation of $P W_{B}$, obtained as:

$P W_{B}=-97.30(1+i)^{-n}-86.14(1+i)^{-n}$

for the first term, $i$ is $12 \%$, which is the prevailing interest rate, while $n$ is the level, which is 1 . The second term has $i$ to be $12 \%$ while $n$ is 2 . The computation yields -155.55 . The performance flow diagram to obtain $P W_{B}, P W_{C}$, and $P W_{T}$ are in Figures $1 \mathrm{a}, 1 \mathrm{~b}, 1 \mathrm{c}$, and $1 \mathrm{~d}$, respectively. 
Table 6. $\mathrm{L}_{16}$ orthogonal array, four factors, and $\mathrm{S} / \mathrm{N}$ ratio (with interest rate) values using Taguchi

\begin{tabular}{|c|c|c|c|c|c|c|c|c|c|c|c|}
\cline { 2 - 12 } & \multicolumn{3}{c|}{ Orthogonal array } & \multicolumn{9}{c|}{ Factors } & \multicolumn{2}{c|}{} \\
$\begin{array}{c}\text { Expt. } \\
\text { No. }\end{array}$ & $\mathrm{B}$ & $\mathrm{H}$ & $\mathrm{C}$ & $\mathrm{T}$ & $\mathrm{B}$ & $\mathrm{H}$ & $\mathrm{C}$ & $\mathrm{T}$ & $\mathrm{S} / \mathrm{N}$ ratio & $\begin{array}{c}\text { Interest } \\
\text { rate }\end{array}$ & $\begin{array}{c}\text { Interest- } \\
\text { based S/N } \\
\text { ratio }\end{array}$ \\
\hline 1 & 1 & 1 & 1 & 1 & 5697 & 5020 & 69728 & 84 & -90.90 & 0.12 & -10.91 \\
\hline 2 & 1 & 1 & 1 & 2 & 5697 & 5020 & 69728 & 300 & -90.90 & 0.12 & -10.91 \\
\hline 3 & 1 & 1 & 2 & 1 & 5697 & 5020 & 298031 & 84 & -103.47 & 0.12 & -12.42 \\
\hline 4 & 1 & 1 & 2 & 2 & 5697 & 5020 & 298031 & 300 & -103.47 & 0.12 & -12.42 \\
\hline 5 & 1 & 2 & 1 & 1 & 5697 & 23605 & 69728 & 84 & -91.34 & 0.12 & -10.96 \\
\hline 6 & 1 & 2 & 1 & 2 & 5697 & 23605 & 69728 & 300 & -91.34 & 0.12 & -10.96 \\
\hline 7 & 1 & 2 & 2 & 1 & 5697 & 23605 & 298031 & 84 & -103.49 & 0.12 & -12.42 \\
\hline 8 & 1 & 2 & 2 & 2 & 5697 & 23605 & 298031 & 300 & -103.49 & 0.12 & -12.42 \\
\hline 9 & 2 & 1 & 1 & 1 & 25693 & 5020 & 69728 & 84 & -91.42 & 0.12 & -10.97 \\
\hline 10 & 2 & 1 & 1 & 2 & 25693 & 5020 & 69728 & 300 & -91.42 & 0.12 & -10.97 \\
\hline 11 & 2 & 1 & 2 & 1 & 25693 & 5020 & 298031 & 84 & -103.50 & 0.12 & -12.42 \\
\hline 12 & 2 & 1 & 2 & 2 & 25693 & 5020 & 298031 & 300 & -103.50 & 0.12 & -12.42 \\
\hline 13 & 2 & 2 & 1 & 1 & 25693 & 23605 & 69728 & 84 & -91.82 & 0.12 & -11.02 \\
\hline 14 & 2 & 2 & 1 & 2 & 25693 & 23605 & 69728 & 300 & -91.82 & 0.12 & -11.02 \\
\hline 15 & 2 & 2 & 2 & 1 & 25693 & 23605 & 298031 & 84 & -103.52 & 0.12 & -12.42 \\
\hline 16 & 2 & 2 & 2 & 2 & 25693 & 23605 & 298031 & 300 & -103.52 & 0.12 & -12.42 \\
\hline
\end{tabular}

B - Beer issued into filler (HL); H - Hectolitres into FBS (HL); C - Crates into FBS (Units); T - Total time available (hours); $\mathrm{S} / \mathrm{N}$ ratio - Signal-to-noise ratio

Table 7. Taguchi average $\mathrm{S} / \mathrm{N}$ ratio (with interest rate) response table

\begin{tabular}{|c|c|c|c|c|}
\hline Level & $\mathrm{B}$ & $\mathrm{H}$ & $\mathrm{C}$ & $\mathrm{T}$ \\
\hline 1 & $-11.68^{*}$ & $-11.68^{*}$ & $-8.23^{*}$ & $-11.69^{*}$ \\
\hline 2 & -11.71 & -11.71 & -9.32 & $-11.69^{*}$ \\
\hline Delta & 0.03 & 0.02 & 1.09 & 0.00 \\
\hline Rank & 2 & 3 & 1 & 4 \\
\hline
\end{tabular}

*optimum values

By following the logic used to evaluate $P W_{B}$, the values of $P W_{H}, P W_{C}$ and $P W_{T}$ are obtained as -164.65 , -164.09 , and -164.66 , respectively. Table 4 shows the summarized values of the economic analysis using the present worth method. As the parameters are individually ranked, the ranks are $P W_{B}, P W_{H}, P W_{T}, P W_{C}$ as 1st, 2nd, 3rd and 4th positions, respectively. It implies that the most economically strong parameter is parameter $B$, while parameter $C$ is claimed by the analysis as the least economically strong parameter.

\subsection{Case 2 - Determine $\mathrm{S} / \mathrm{N}$ ratios (with interest rate), optimal parametric settings, and present worth values}

The response table development from the $\mathrm{S} / \mathrm{N}$ ratios (Table 6) is presented in Table 7.

This follows the same procedure carried out in Case 1 except that the interest-based $\mathrm{S} / \mathrm{N}$ ratio replaces the $\mathrm{S} / \mathrm{N}$ ratios. The optimal $\mathrm{S} / \mathrm{N}$ ratios (with interest rate) are $B_{1} H_{1} C_{1} T_{1}$ or $B_{1} H_{1} C_{1} T_{2}$. This is interpreted as 5,697 HL of beer issued into filler with 5,020 HL of hectolitres into FBS and 69, 728 units of crates into FBS and 84 hours of the total time available according to $B_{1} H_{1} C_{1} T_{1}$. However, the interpretation of $B_{1} H_{1} C_{1} T_{1}$ is $5,697 \mathrm{HL}$ of beer issued into filler with $5,020 \mathrm{HL}$ of hectolitres in FBS and 69,728 units of the crate into FBS and $300 \mathrm{hrs}$ of the total time available. In this case, also, two solutions are obtained since we have a delta value of zero for $T$. It means that the two options of $T_{1}$ and $T_{2}$ are feasible. Nonetheless, since $T_{1}<T_{2}$, the earlier is preferred to the later since the interest of the packaging manager is to minimize the total time taken, and $T_{1}$ complies with this choice. The ranking of the parameter is that $C$ is ranked $1^{\text {st }}, B$ is ranked $2^{\text {nd }}, H$ is ranked $3^{\text {rd, }}$ and $T$ is ranked $4^{\text {th }}$. By comparing the results of Cases 1 and 2, it is observed that Case 1 offers the opportunity to know the health status of the plant as there is a final single value, which may be positive or negative upon which the plant's health status is judged. Besides, each parameter is finally judged concerning its strength in maintaining a good health status, indicated in the ranking. However, Case 2 does not provide these details, and Case 1 may be referred to as Case 2. By comparing the optimal parametric setting offered by Cases 1 and 2, it is observed that parameters $H$ and $C$ yielded the same results without reduction in values. Despite his, the incorporation of interest rate into the Case 2 method still presents a more comprehensive model than Case 1, which has none. 
S.A. Oke and I.O.Fagbolagun

Table 8. Present worth (interest rate and inflationary factor) at optimal values of the Taguchi method

\begin{tabular}{|c|c|c|c|c|}
\hline & $\mathrm{PW}_{\mathrm{B}}$ & $\mathrm{PW}_{\mathrm{H}}$ & $\mathrm{PW}_{\mathrm{C}}$ & $\mathrm{PW}_{\mathrm{T}}$ \\
\hline Value & -250.38 & -270.05 & -274.10 & -269.98 \\
\hline Rank & 1 & 3 & 4 & 2 \\
\hline
\end{tabular}

Table 9. $\mathrm{L}_{16}$ orthogonal array, four factors, and $\mathrm{S} / \mathrm{N}$ ratios (with inflation factor) values using the Taguchi method

\begin{tabular}{|c|c|c|c|c|c|c|c|c|c|c|c|}
\hline & \multicolumn{4}{|c|}{ Orthogonal array } & \multicolumn{4}{|c|}{ Factors } & & & \\
\hline $\begin{array}{c}\text { Expt. } \\
\text { No. }\end{array}$ & $\mathrm{B}$ & $\mathrm{H}$ & $\mathrm{C}$ & $\mathrm{T}$ & B & $\mathrm{H}$ & $\bar{C}$ & $\mathrm{~T}$ & $\mathrm{~S} / \mathrm{N}$ ratio & $\begin{array}{c}\text { Inflation } \\
\text { factor }\end{array}$ & $\begin{array}{c}\text { Inflation } \\
\text { factor- } \\
\text { based } S / N \\
\text { ratio }\end{array}$ \\
\hline 1 & 1 & 1 & 1 & 1 & 5697 & 5020 & 69728 & 84 & -90.90 & 0.1724 & -15.67 \\
\hline 2 & 1 & 1 & 1 & 2 & 5697 & 5020 & 69728 & 300 & -90.90 & 0.1724 & -15.67 \\
\hline 3 & 1 & 1 & 2 & 1 & 5697 & 5020 & 298031 & 84 & -103.47 & 0.1724 & -17.84 \\
\hline 4 & 1 & 1 & 2 & 2 & 5697 & 5020 & 298031 & 300 & -103.47 & 0.1724 & -17.84 \\
\hline 5 & 1 & 2 & 1 & 1 & 5697 & 23605 & 69728 & 84 & -91.34 & 0.1724 & -15.75 \\
\hline 6 & 1 & 2 & 1 & 2 & 5697 & 23605 & 69728 & 300 & -91.34 & 0.1724 & -15.75 \\
\hline 7 & 1 & 2 & 2 & 1 & 5697 & 23605 & 298031 & 84 & -103.49 & 0.1724 & -17.84 \\
\hline 8 & 1 & 2 & 2 & 2 & 5697 & 23605 & 298031 & 300 & -103.49 & 0.1724 & -17.84 \\
\hline 9 & 2 & 1 & 1 & 1 & 25693 & 5020 & 69728 & 84 & -91.42 & 0.1724 & -15.76 \\
\hline 10 & 2 & 1 & 1 & 2 & 25693 & 5020 & 69728 & 300 & -91.42 & 0.1724 & -15.76 \\
\hline 11 & 2 & 1 & 2 & 1 & 25693 & 5020 & 298031 & 84 & -103.50 & 0.1724 & -17.84 \\
\hline 12 & 2 & 1 & 2 & 2 & 25693 & 5020 & 298031 & 300 & -103.50 & 0.1724 & -17.84 \\
\hline 13 & 2 & 2 & 1 & 1 & 25693 & 23605 & 69728 & 84 & -91.82 & 0.1724 & -15.83 \\
\hline 14 & 2 & 2 & 1 & 2 & 25693 & 23605 & 69728 & 300 & -91.82 & 0.1724 & -15.83 \\
\hline 15 & 2 & 2 & 2 & 1 & 25693 & 23605 & 298031 & 84 & -103.52 & 0.1724 & -17.85 \\
\hline 16 & 2 & 2 & 2 & 2 & 25693 & 23605 & 298031 & 300 & -103.52 & 0.1724 & -17.85 \\
\hline
\end{tabular}

B - Beer issued into filler (HL); H - Hectolitres into FBS (HL); C - Crates into FBS (Units); T - Total time available (hours); S/N ratio - Signal-to-noise ratio

\subsection{Case 3 - Determine $\mathrm{S} / \mathrm{N}$ ratios, optimal parametric settings, and present worth with inflation factor}

Table 2 was used to determine the $\mathrm{S} / \mathrm{N}$ ratios, and the final values of the optimal parametric setting obtained in Case 1 are used. This is revealed in Table 3. However, to analyze the results using present worth integrated with the inflation factor, Equation (6) is used. We start computation with the parameter $B$. the value of PWB is $\left.P W_{B}=-97.30\left[(1+i)^{-n}\right](1+\beta)^{n}\right]-86.14\left[(1+i)^{-n}\right]$

$$
\left[(1+\beta)^{n}\right]
$$

This gives

$$
\begin{gathered}
P W_{B}=-97.30\left[(1+0.12)^{-1}\left[(1+0.1724)^{1}\right]-86.14\right. \\
{\left[(1+0.12)^{-2}\left[(1+0.1724)^{2}\right]\right.}
\end{gathered}
$$

However, it was noted that $i=12 \%$ is the interest rate while the value of $B$, the inflationary factor obtained from the National Bureau of Statistics in Nigeria, gives $17.24 \%$. The final value, $P W_{B}$, is -250.38 . Similarly, all other values are calculated, and the values are summarized in Table 8. Notice that Figures 1a to $1 \mathrm{~d}$ were used in the computation. It follows in the flow of the elements. However, the multiplier differs when the combined interest rate and inflationary factor replace the interest rate, and the inflationary factor replaces the interest rate alone. The interpretation is that when the interest rate and inflationary factor are combined while the parameters are optimized concurrently, the best parameter is $P W_{B}$ with a value of -250.30 , the second rank goes to $P W_{T}$ with a value of -269.98 while the third position goes to $P W_{H}$ with a value of -270.05 and the last parameter is $P W_{C}$ with a value of -274.10 . Notice that the results for this method incorporate the optimal parametric setting based on Case 1 and the present worth results (inflationary factor and interest rate, combined). By comparing the results of Case 1 and Case 3, Case 1 appears to give lower present values for all the parameters. The reason is that Case 3 accounts for the inflationary factor in addition to the only interest rate that Case 1 accounts for. Case 3 is still superior to Case 1 as it gives a holistic view of the environment. However, it could be argued that when there is inflation in an economy, the interest factor is adjusted. This may not be true as governments often peg down the interest rate to control the economy. Small-scale traders and manufacturers may not perform well if the government fails to restrict the interest rate for borrowed money in financial houses.

\subsection{Case 4 - Determine $S / N$ ratios (with inflation factor), optimal parametric setting, and present worth values}

For Case 4, the $\mathrm{S} / \mathrm{N}$ ratios (with inflationary factor) are shown in Table 9. By following the procedure to determine the optimal parametric settings, where 
Table 10. Taguchi average $\mathrm{S} / \mathrm{N}$ ratio (with inflation factor) response table

\begin{tabular}{|c|c|c|c|c|}
\hline Level & $\mathrm{B}$ & $\mathrm{H}$ & $\mathrm{C}$ & $\mathrm{T}$ \\
\hline 1 & $-16.77^{*}$ & $-16.78^{*}$ & $-11.82^{*}$ & $-16.80^{*}$ \\
\hline 2 & -16.82 & -16.82 & -13.38 & $-16.80^{*}$ \\
\hline Delta & 0.05 & 0.04 & 1.57 & 0.00 \\
\hline Rank & 2 & 3 & 1 & 4 \\
\hline
\end{tabular}

*optimum values

Beneficial side

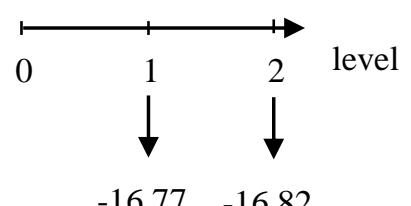

Non-beneficial side

Figure 2a. Present worth for parameter B

Beneficial side

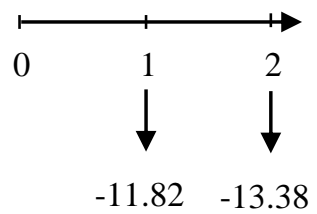

Non-beneficial side

Figure 2c. Present worth for parameter C
Beneficial side

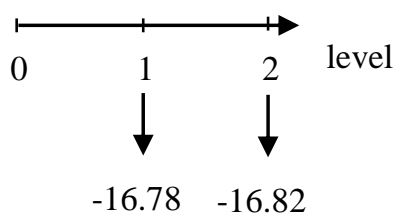

Non-beneficial side

Figure 2b. Present worth for parameter $\mathrm{H}$

Beneficial side

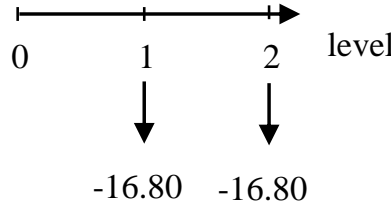

Non-beneficial side

Figure 2d. Present worth for parameter T

Table 11. Present worth at optimal values of Taguchi method (inflationary factor incorporated)

\begin{tabular}{|l|l|l|l|l|}
\hline & $\mathrm{PW}_{\mathrm{B}}$ & $\mathrm{PW}_{\mathrm{H}}$ & $\mathrm{PW}_{\mathrm{C}}$ & $\mathrm{PW}_{\mathrm{T}}$ \\
\hline Value & -28.38 & -28.39 & -21.22 & -28.39 \\
\hline Rank & 2 & 3 & 1 & 3 \\
\hline
\end{tabular}

averages are made based on the level indication from the orthogonal matrix, Table 10 is computed.

The optimal parametric settings for Case 4 is $B_{1} H_{1} C_{1} T_{1}$ or $B_{1} H_{1} C_{1} T_{2}$, translated as $5,697 \mathrm{HL}$ of beer issued into filler with $5,020 \mathrm{HL}$ of hectolitres into FBS and 69,728 units of crates into FBS and finally 84 hours or 300 hours of the total time available, depending on whether $T_{1}$ or $T_{2}$ is chosen as a parametric value for the optimal parametric setting. The ranking by this Case 4 is parameters $C, B, H$, and $T$ as the $1^{\text {st }}, 2^{\text {nd }}, 3^{\text {rd }}$ and $4^{\text {th }}$ parameters, respectively (Table 10). To analyze the present worth of the parameters, Equation (2) is reintroduced. This yields the values obtained through Figures $2 \mathrm{a}, 2 \mathrm{~b}, 2 \mathrm{c}$, and $2 \mathrm{~d}$, respectively. The final Table 11 for the present worth gives ranks of $P W_{C}, P W_{B}, P W_{H}$, and $P W_{T}$ as the $1^{\text {st }}, 2^{\text {nd }}$, and $3^{\text {rd }}$, respectively.

\subsection{Case 5 - Determine $S / N$ ratios (with interest rate and inflation factor), optimal parametric setting}

For Case 5, the $\mathrm{S} / \mathrm{N}$ ratios (with combined interest rate and inflationary factor) are shown in Table 12.
By following the procedure to develop Table 2, the optimal parametric setting is established (Table 13) as $\mathrm{B}_{1} \mathrm{H}_{1} \mathrm{C}_{2} \mathrm{~T}_{1}$ or $\mathrm{B}_{1} \mathrm{H}_{1} \mathrm{C}_{2} \mathrm{~T}_{2}$, which is interpreted as follows. It is 5,697 HL of beer issued into filler with 5,020 HL of hectolitres into FBS and 69728 units of crates into FBS and 84 hours or 300 hours of the total time available whether $T_{1}$ or $T_{2}$ is considered as the last parameter.

A summary of results for all the cases is shown in Table 14. From Table 14, the optimum parameter setting for each case was different following the introduction of the interest rate and inflation rate. This is consistent with the results of previous research, which examined the effect of interest rate and inflation on a production setup, demonstrated in Kuchta (2008), Zizlavsky (2014), and Maravas and Pantouvakis (2018). 
Table 12. $\mathrm{L}_{16}$ orthogonal array, four factors, and $\mathrm{S} / \mathrm{N}$ ratio (with interest rate and inflationary factor) values using Taguchi method

\begin{tabular}{|c|c|c|c|c|c|c|c|c|c|c|c|c|}
\hline & \multicolumn{4}{|c|}{ Orthogonal array } & \multicolumn{4}{|c|}{ Factors } & \multirow[b]{2}{*}{$\begin{array}{c}\mathrm{S} / \mathrm{N} \\
\text { ratio }\end{array}$} & \multirow[b]{2}{*}{$\begin{array}{c}\text { Interest } \\
\text { rate }\end{array}$} & \multirow[b]{2}{*}{$\begin{array}{l}\text { Inflation } \\
\text { factor }\end{array}$} & \multirow[b]{2}{*}{$\begin{array}{l}\text { Interest- } \\
\text { inflation } \\
\text { factor- } \\
\text { based } \mathrm{S} / \mathrm{N} \\
\text { ratio }\end{array}$} \\
\hline $\begin{array}{c}\text { Expt. } \\
\text { No. }\end{array}$ & B & $\mathrm{H}$ & $\mathrm{C}$ & $\mathrm{T}$ & B & $\mathrm{H}$ & $\mathrm{C}$ & $\mathrm{T}$ & & & & \\
\hline 1 & 1 & 1 & 1 & 1 & 5697 & 5020 & 69728 & 84 & -90.90 & 0.12 & 0.1724 & -1.88 \\
\hline 2 & 1 & 1 & 1 & 2 & 5697 & 5020 & 69728 & 300 & -90.90 & 0.12 & 0.1724 & -1.88 \\
\hline 3 & 1 & 1 & 2 & 1 & 5697 & 5020 & 298031 & 84 & 103.47 & 0.12 & 0.1724 & -2.14 \\
\hline 4 & 1 & 1 & 2 & 2 & 5697 & 5020 & 298031 & 300 & -103.47 & 0.12 & 0.1724 & -2.14 \\
\hline 5 & 1 & 2 & 1 & 1 & 5697 & 23605 & 69728 & 84 & -91.34 & 0.12 & 0.1724 & -1.89 \\
\hline 6 & 1 & 2 & 1 & 2 & 5697 & 23605 & 69728 & 300 & -91.34 & 0.12 & 0.1724 & -1.89 \\
\hline 7 & 1 & 2 & 2 & 1 & 5697 & 23605 & 298031 & 84 & -103.49 & 0.12 & 0.1724 & -2.14 \\
\hline 8 & 1 & 2 & 2 & 2 & 5697 & 23605 & 298031 & 300 & -103.49 & 0.12 & 0.1724 & -2.14 \\
\hline 9 & 2 & 1 & 1 & 1 & 25693 & 5020 & 69728 & 84 & -91.42 & 0.12 & 0.1724 & -1.89 \\
\hline 10 & 2 & 1 & 1 & 2 & 25693 & 5020 & 69728 & 300 & -91.42 & 0.12 & 0.1724 & -1.89 \\
\hline 11 & 2 & 1 & 2 & 1 & 25693 & 5020 & 298031 & 84 & -103.50 & 0.12 & 0.1724 & -2.14 \\
\hline 12 & 2 & 1 & 2 & 2 & 25693 & 5020 & 298031 & 300 & -103.50 & 0.12 & 0.1724 & -2.14 \\
\hline 13 & 2 & 2 & 1 & 1 & 25693 & 23605 & 69728 & 84 & -91.82 & 0.12 & 0.1724 & -1.90 \\
\hline 14 & 2 & 2 & 1 & 2 & 25693 & 23605 & 69728 & 300 & -91.82 & 0.12 & 0.1724 & -1.90 \\
\hline 15 & 2 & 2 & 2 & 1 & 25693 & 23605 & 298031 & 84 & -103.52 & 0.12 & 0.1724 & -2.14 \\
\hline 16 & 2 & 2 & 2 & 2 & 25693 & 23605 & 298031 & 300 & -103.52 & 0.12 & 0.1724 & -2.14 \\
\hline
\end{tabular}

B - Beer issued into filler (HL); H - Hectolitres into FBS (HL); C - Crates into FBS (Units); T - Total time available (hours); S/N ratio - Signal-to-noise ratio

Table 13. Taguchi average $\mathrm{S} / \mathrm{N}$ ratio (with interest rate) response table

\begin{tabular}{|c|c|c|c|c|}
\hline Level & $\mathrm{B}$ & $\mathrm{H}$ & $\mathrm{C}$ & $\mathrm{T}$ \\
\hline 1 & $-2.01^{*}$ & $-2.01^{*}$ & $-1.42^{*}$ & $-2.02^{*}$ \\
\hline 2 & -2.02 & -2.02 & -1.61 & $-2.02^{*}$ \\
\hline Delta & 0.00 & 0.00 & 0.19 & 0.00 \\
\hline Rank & 2 & 2 & 1 & 2 \\
\hline
\end{tabular}

*optimum values

Table 14. Summarized optimal values of packaging process parameters

\begin{tabular}{|c|c|c|c|}
\hline Case & Optimum parameters & Present worth (interest rate) & $\begin{array}{l}\text { Present worth (interest } \\
\text { rate + inflation factor) }\end{array}$ \\
\hline $\begin{array}{l}\text { Case } 1-\text { Determine } \mathrm{S} / \mathrm{N} \text { ratios, } \\
\text { optimal parametric settings, and } \\
\text { present worth values }\end{array}$ & $\begin{array}{l}B_{2} H_{1} C_{1} T_{1} \text { or } B_{2} H_{1} \\
C_{1} T_{2} \\
B, C, H, T \text { as } 1 \text { st, 2nd, } \\
\text { 3rd, and 4th positions }\end{array}$ & $\begin{array}{l}P W_{B}, P W_{H}, P W_{T}, P W_{C} \text { as } \\
1 \text { st, 2nd, } 3^{\text {rd, } \text { and } 4 \text { th }} \\
\text { positions }\end{array}$ & - \\
\hline $\begin{array}{l}\text { Case 2- Determine } \mathrm{S} / \mathrm{N} \text { ratios } \\
\text { (with interest rate), optimal } \\
\text { parametric settings }\end{array}$ & $\begin{array}{l}B_{2} H_{2} C_{2} T_{1} \text { or } B_{2} H_{2} C_{2} T_{2} \\
C, B, H, T \text { as } 1 \mathrm{st}, 2 \mathrm{nd}, 3 \mathrm{rd}, \\
\text { and } 4 \text { th positions }\end{array}$ & - & - \\
\hline $\begin{array}{l}\text { Case } 3 \text { - Determine } \mathrm{S} / \mathrm{N} \text { ratios, } \\
\text { optimal parametric settings and } \\
\text { present worth with inflation factor }\end{array}$ & & - & $\begin{array}{l}P W_{B}, P W_{T}, P W_{H}, P W_{C} \\
\text { as } 1 \mathrm{st}, 2^{\text {nd }}, 3 \text { rd, and } 4 \text { th } \\
\text { positions }\end{array}$ \\
\hline $\begin{array}{l}\text { Case } 4 \text { - Determine } \mathrm{S} / \mathrm{N} \text { ratios } \\
\text { (with inflation factor), optimal } \\
\text { parametric setting, and present } \\
\text { worth values }\end{array}$ & $\begin{array}{l}B_{1} H_{1} C_{1} T_{1} \text { or } B_{1} H_{1} C_{1} T_{2} C, \\
B, H, T \text { as } 1 \text { st, } 2 \text { nd, } 3 \mathrm{rd}, \\
\text { and } 4 \text { th positions }\end{array}$ & - & $\begin{array}{l}P W_{C}, P W_{B}, P W_{H}, P W_{T} \\
\text { as } 1 \mathrm{st}, 2^{\text {nd }}, 3 \mathrm{rd} \text {, and } 3 \mathrm{rd} \\
\text { positions }\end{array}$ \\
\hline $\begin{array}{l}\text { Case } 5 \text { - Determine } \mathrm{S} / \mathrm{N} \text { ratios } \\
\text { (with interest rate and inflation } \\
\text { factor), optimal parametric setting }\end{array}$ & $\begin{array}{l}B_{1} H_{1} C_{1} T_{1} \text { or } B_{1} H_{1} C_{1} T_{2} \\
C, B, H, T \text { as } 1 \text { st, } 2 \text { nd, } 3 \mathrm{rd}, \\
\text { and } 4 \text { th positions }\end{array}$ & & \\
\hline
\end{tabular}




\subsection{Validation of method with cold arc welding parametric data}

In this article, a novel method is claimed to incorporate the economic aspects in the application process of the Taguchi method, and the conclusions of this study were based on the results of the brewery industry process. However, there is a need to confirm that it will continue to function effectively for a newly developed method. This has motivated the use of a different work setting, the welding system, to confirm the effectiveness of the developed economic-based model for the Taguchi method. It is important to confirm the effectiveness of the method since as one acknowledges the challenges at the different stages of application of the model, it could be fine-tuned for enhanced performance.

The newly developed extension to the Taguchi method was tested on a published work with the following results. The case studied is Sadin et al. (2019), which examines cold arc welding parameters. Table 6 of the paper was worked upon with the following results. Case 1 (Equation (2)) in our work was deployed to this Table 6 while $P W_{W C}, P W_{W V}$, and $P W_{W S}$ were computed as the present worth of welding current, welding voltage, and welding speed, respectively. $P W_{W C}$ is obtained having decided whether the parameters are beneficial or non-beneficial. In welding, it is assumed that welding current, welding voltage, and welding

Beneficial side

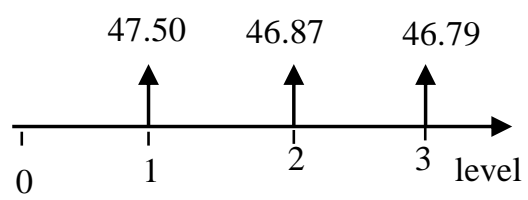

Non-beneficial side

Figure 3a. Present worth for parameter WC speed are beneficial parameters. So they are on the positive side of the performance flow diagram.

$$
P W_{W C}=47.5(1+i)^{-n}+46.87(1+i)^{-n}+46.79(1+i)^{-n}
$$

where $i$ is the interest rate at $12 \%$ while $n$ for the first, second and third terms are 1,2 and 3, respectively. Therefore $P W_{W C}=113.08$ while $P W_{W W}$ and $P W_{W S}$ are 112.98 and 113.04 , respectively.

The associated diagrams are in Figures $3 a, 3 b$, and $3 \mathrm{c}$, while Table 5 produces the ranks. The new ranks according to the present worth application of the Taguchi method-present worth method are $P W_{W C}$ as first, $P W_{W S}$ as second, and $P W_{W V}$ as the third-ranked.

Compared with Sabdin et al. (2019) for the ranking of the optimal parameters, there is conflict. $W S, W V$, and $W C$ are grouped as first, second, and third, respectively. Since our work is an economic evaluation, there is a possibility of divergence in results.

\subsection{Summary of results}

In the present study, an optimization of the packaging process was attempted to reduce beer waste. Furthermore, an economic dimension is introduced to assess the plant for sustainable practices. The obtained key results are summarized as follows:

1. Table 3 reveals the optimal parametric setting. The best parameter is the beer issued into the filler, while the worst parameter is time. The table reveals that

Beneficial side

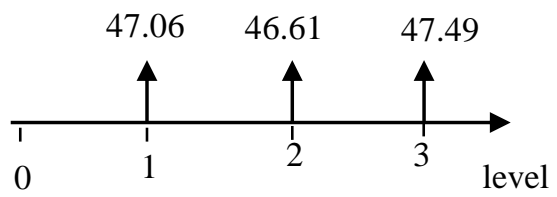

Non-beneficial side

Figure 3b. Present worth for parameter WV

Beneficial side

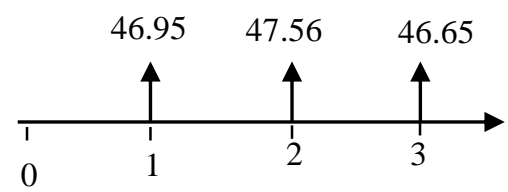

Non-beneficial side

Figure 3c. Present worth for parameter WS

Table 15. Present worth at optimal values of Taguchi method based on analysis of data from Sabdin et al. (2019)

\begin{tabular}{|c|c|c|c|}
\hline & $\mathrm{PW}_{\mathrm{WC}}$ & $\mathrm{PW}_{\mathrm{WV}}$ & $\mathrm{PW}_{\mathrm{WS}}$ \\
\hline Value & 113.08 & 112.98 & 113.04 \\
\hline Rank & 1 & 3 & 2 \\
\hline
\end{tabular}


proper control of the beer issued into the filler should be exercised to guarantee the efficiency and profitability of the brewery. Leakages in this area may be eliminated by intensive lean management practices and the education of operators.

2. Table 4 shows the present worth of the plant at an optimized threshold. The parameter beer issued into the filler was also taken as the best and hence the most sensitive one to concentrate on. This signifies the influential attribute of the parameter for continued plant operation. This also indicates that significant improvement efforts should be directed to this parameter to guarantee the economic progress of the plant.

3. Table 5 reveals that the present worth of the parameter, welding current is the best and most sensitive in the process. If higher productivity in the welding activity is to be guaranteed, efforts to improve this parameter should be made above other parameters.

The above results reveal that the proposed method may be suitable for the brewing process especially considering the packaging unit. Consequently, it may be suitable in the management decision process where the ability of the plant to retire debts is given important consideration.

\section{CONCLUSIONS}

In this paper, an effort was made to extend the classical Taguchi method by incorporating an economic dimension, which is critical for the sustenance of the industry. Today, the technical competence of the plant is not enough; economic sustainability is a strong determinant of sustainable manufacturing processes. An $\mathrm{L}_{16}$ orthogonal array was defined for the four-factor twolevel framework, the signal-to-noise ratio computed, and the response table with the associated parametric setting determined. The novel aspect is the establishment of a present worth method at the optimal parametric setting instance. The levels replaced the time element while the interest rate is introduced, and the present worth method is used to evaluate all the parameters in a ranking system. The findings from the analysis of field data revealed that the optimal parametric setting for each case was different following the introduction of interest rate and inflation rate. This affects the planning culture of the manager at the strategic level and the conduct of operators at the operational level. Managers developing strategies to optimize the performance of packaging plants now could plan for a company-wide campaign and economic aspects of the business through a display of posters at strategic places within the factory floor. They also train the workers to develop a culture that production time should be handled as an economic resource and otherwise economic disaster for the company may set it. At the operational level, supervisors are to constantly remind their subordinates of the need for a new order of culture in the economic utilization of available production time and all resources at the factory floor.
The results indicate that the proposed Taguchi methodpresent worth method is adequate for controlling beer waste in a brewery process. The method has the advantage of being sensitive to the interest rate as production processes are not run in isolation but are influenced by the time value of money.

Moreover, the method was proved to be suitable for the cold arc welding process that is central to developments in industrial piping, railroads, manufacturing plants, maintenance and repairs, and shipbuilding. The purpose of creating Cases 1 to 5 is to show the wide-ranging circumstances with which the economic/financial factors could influence the optimization of process parameters in the packaging plant. The specific case to apply in a circumstance depends on which of the two factors, interest rate or the inflation rate, is the predominantly influential factor for the company's business environment. In countries where the inflation rate is three digits, preference may be given to the Case with the inflation rate. Nonetheless, some packaging companies may prefer a model that incorporates both the interest rate and inflation factor. In this instance, Case 4 may be chosen. Future studies may tackle the incorporation of inflationary rates and opportunity costs.

\section{REFERENCES}

Abafi, J., \& Oke, A. (2020). Analysis of downtime in a typical Nigerian multinational bottling company. Journal of Engineering Studies and Research, 26(3), 88-96.

Aerts, G., \& Smits, T. (2017). The package size effect: How package size affects young children's consumption of snacks differing in sweetness. Food Quality and Preference, 60, 72-80.

Almetwally, A.A. (2020). Multi-objective optimization of woven fabric parameters using Taguchi-grey relational analysis. Journal of Natural Fibers, 17(10), 1468-1478.

Al-Refaie, A. (2014). Optimisation of multiple responses in the Taguchi method using fuzzy regression. Artificial Intelligence for Engineering Design, Analysis, and Manufacturing, 28, 99-107.

Al-Refaie, A. (2015). A proposed weighted additive model to optimise multiple quality responses in the Taguchi method with applications. Proceedings of the Institution of Mechanical Engineers, Part E: Journal of Process Mechanical Engineering, 229(3), 168-178.

Anthony, J. (2001). Simultaneous optimisation of multiple quality characteristics in manufacturing processes using Taguchi's quality loss function. The International Journal of Advanced Manufacturing Technology, 17(2), 134-138.

Appadoo, S.S. (2014). Probabilistic fuzzy net present value model and application, mathematical problems 
in Engineering. Mathematical Problem in Engineering, 2014, 1-11.

Athreya, S., \& Venkatesh, Y.D. (2012). Application of Taguchi method for optimization of process parameters in improving the surface roughness of lathe facing operation. International Refereed Journal of Engineering and Science, 1(3), 13-19.

Blackhall, R.B., Ritchie, J.M., Baxter, L.F., \& Black, I. (2006). The novel combination of Taguchi methods and texture profile analysis applied to the optimisation of laboratory-based biscuit manufacturing. Proceedings of the Institution of Mechanical Engineers, Part B: Journal of Engineering Manufacture, 220(2), 273-293.

Candan, G., \& Yazgan, H.R. (2015). Genetic Algorithm parameter optimisation using Taguchi method for a flexible manufacturing system scheduling problem. International Journal of Production Research, 53(3), 897-915.

Chomsamutr, K., \& Jongprasithporn, S. (2012). Optimisation parameters of tool-life model using taguchi approach and response surface methodology. International Journal of Computer Science Issues, 9(1), 120

Chandrasekar, V., Kannan, K., Priyavarshini, R., \& Gayathri, R. (2015). Application of Taguchi method in optimization of process factors of ready to eat peanut (Arachis Hypogaea) Chutney. International Food Research Journal, 22(2), 510-516.

Chen, F.C., Tzeng, Y.F., Chen, W.R., \& Hsu, M.H (2009). The use of the Taguchi method and principal component analysis for the sensitivity analysis of a dual-purpose six-bar mechanism. Proceedings of the Institution of Mechanical Engineers, Part C: Journal of Mechanical Engineering Science, 223(3), 733-741.

Chen, F.C., \& Huang, H.H. (2006). Taguchi-fuzzy-based approach for the sensitivity analysis of a four-bar function generator. Proceedings of the Institution of Mechanical Engineers Part C: Journal of Mechanical Engineering Science, 220(9), 1413-1421.

Chiu, C.Y., \& Park, C.S. (1994). Fuzzy cash flow analysis using present worth criterion. The Engineering Economist: A Journal Devoted to the Problems of Capital Investment, 39(2), 113-138.

Doss, D.A., Jones, D.W., Sumrall, W., Henley, R., McErneath, D., Lackey, H., \& Gokaraju, B. (2015). A net present worth analysis of considered academic programs at a private regional higher educational institution. Journal of Interdisciplinary Studies in Education, 4(1), 55-77.

Dwiwedi, A.K.R., \& Kumar, S. (2015). Practical application of Taguchi method for optimization of process parameters in Injection molding machine for PP material. International Research Journal of Engineering and Technology, 2(4), 264-268.

Fang, Z., Zhao, Y., Warner, R.D., \& Johnson, S.K. (2017). Active and intelligent packaging in meat industry. Trends in Food Science and Technology, 61, 60-71.

Fagbolagun, I.O., \& Oke, S.A. (2020). The optimisation of packaging system process parameters using Taguchi method. International Journal of Industrial Engineering and Engineering Management, 2(1), 113.

Ganesan, V. \& Kaliyamoorthy, B. (2020). Utilization of Taguchi technique to enhance the interlaminar shear strength of wood dust filled woven jute fiber reinforced polyester composites in cryogenic environment. Journal of Natural Fibers, 17(8), 1-12.

Grobbel, J.P., Dikeman, M.E., Hunt, M.C., \& Williken, G.A. (2008). Effects of packaging atmospheres on beef instrumental tenderness, fresh color stability, and internal cooked color. Journal of Animal Science, 86(5), 1191-1199.

Hamdar, B.C., Khalil, A., Bissani, M., \& Kalaydjian, N. (2018). Economic assessment of the impact of packaging design on consumption. Economics, 7(2), 27-33

Heide, M., \& Olsen, S.O. (2017). Influence of packaging attributes on consumer evaluation of fresh cod. Food Quality and Preference, 60, 9-18.

Ishrat, S.I., Khan, Z.A., Siddiquee, A.N., Badruddin, I.A., Algahtani, A., Javaid, S., \& Gupta, R. (2019). Optimising parameters for expanded polystyrene based pod production using Taguchi method, Mathematics, 7(9), 847.

Jou, Y.T., Lin, W.T., Lee, W.C., \& Yeh, T.M. (2014). Integrating the Taguchi method and response surface methodology for process parameter optimization of the injection molding. Applied Mathematics \& Information Sciences, 8(3), 1277-1285.

Karabegović, E., \& Đuzelić, R. (2019). The optimization of thermoforming process parameters in the packaging of medical products. Advanced Technologies and Materials, 44(2), 21-24.

Karimi, P., Mahdieh, O., \& Rahmani, M. (2013). The study of relationship between packaging elements and purchase behaviour-consumers of good, cosmetics and health products. Interdisciplinary Journal of Contemporary Research in Business, 5(3), 281-295.

Kahraman, C. (2001). Capital budgeting techniques 
using Discounted Fuzzy Cash Flows. In D. Ruan, J. Kacprzyk, \& M. Fedrizzi, Soft Computing for Risk Evaluation and Management: Studies in Fuzziness and Soft Computing. Heidelberg: Physica.

Kuchta, D. (2008) Optimization with Fuzzy Present Worth analysis and applications. In C. Kahraman, Fuzzy Engineering Economics with Applications: Studies in Fuzziness and Soft Computing. Heidelberg: Springer.

Maravas, A., \& Pantouvakis, J.P. (2018). A new approach to studying net present value and the internal rate of return of engineering projects under uncertainty with three-dimensional graphs. Advances in Civil Engineering, 2018, 1-9.

McMillin, K.W. (2017). Advancements in meat packaging. Meat Science, 132, 153-162.

Sabdin, S.D., Husein, N.I.S., Sued, M.K., Ayob, M.S., Rahiim, M.A.S.A., \& Fadzil, M. (2019). Effects of cold arc welding parameters on the trestle strength of high-strength steel plate investigated using the Taguchi approach. Journal of Mechanical Engineering and Sciences, 13(2), 4846-4856.

Silayoi, P., \& Speece, M. (2007). The importance of packaging attributes: A conjoint analysis approach. European Journal of Marketing, 41(11-12), 14951517.
Sousa, M.R.S., Lora-García, J., López-Pérez, M.F., Santafé-Moros, A., \& Gozálvez-Zafrilla, J.M. (2020). Operating conditions optimization via the Taguchi method to remove colloidal substances from recycled paper and cardboard production wastewater. Membranes, 10(8), 170.

Steenis, N.D., Herpen, E., van der Lans, I.A., Ligthart, T.N., \& van Trijp, H.C.M. (2017). Consumer response to packaging design: The role of packaging materials and graphics in sustainability perceptions and product evaluations. Journal of Cleaner Production, 162, 286298.

Üstüntağ, S., Şenyiğit, E., Mezarciöz, S., \& Türksoy, H.G. (2020). Optimization of coating process conditions for denim fabrics by Taguchi method and Grey relational analysis. Journal of Natural Fibers, 17(8), 1-15.

Zagloel, T.Y., \& Al-Aina, F. (2009). Gram optimisation using Taguchi method of parameter design and neural network process model in packaging industry. Proceedings of 2nd Asia Pacific Conference in Manufacturing System, Indonesia.

Zizlavsky, O. (2014). Net present value approach: Method for economic assessment of innovation projects. Procedia-Social and Behavioral Sciences, 156, 506-512. 